\title{
HUBUNGAN ANTARA PENGETAHUAN IBU TENTANG CARA MENYENDAWAKAN BAYI USIA 0 - 6 BULAN DENGAN KEJADIAN GUMOH SESUDAH MENYUSUI DI PUSKESMAS MANUKAN KULON.
}

\author{
Katrina Loisa Bernadus ${ }^{1}$ dan Ika Dwi Lestari ${ }^{2}$ \\ 1.Tenaga Pengajar Prodi D-III Kebidanan Universitas PGRI Adi Buana Surabaya \\ 2. Mahasiswa Prodi D-III Kebidanan Universitas PGRI Adi Buana Surabaya
}

\begin{abstract}
ABSTRAK
Penyebab kematian bayi antara lain karena infeksi saluran nafas $27,6 \%$ dan infeksi saluran cerna 4,3\%. Salah satu gangguan pencernaan yang sering terjadi pada bayi usia 0-12 bulan adalah gumoh. Data di kelurahan Lontar terdapat 30 bayi yang berusia 0-6 bulan masingmasing pernah mengalami gumoh. Penelitian ini bertujuan menganalisis hubungan antara pengetahuan ibu tentang cara menyendawakan bayi sesudah menyusui dengan kejadian gumoh pada bayi usia $0-6$ bulan. Desain penelitian yang digunakan adalah koreksi dan uji statistic menggunakan rumus Spearman Rank Order Correlation. Dari 30 responden sebagian besar ibu mempunyai pengetahuan cukup, sebagian besar bayimengalami kejadian gumoh jarang dan dapat disimpulkan terdapat hubungan antara pengetahuan tentang cara menyendawakan bayi sesudah menyusui dengan kejadian gumoh pada bayi usia $0-6$ bulan. Oleh karena itu perlu diadakan penyuluhan tentang cara menyendawakan bayi.
\end{abstract}

Kata Kunci: Pengetahuan Ibu, Kejadian Gumoh.

\section{PENDAHULUAN}

Gumoh adalah keluarnya kembali sebagian susu yang telah ditelan melalui mulut dan tanpa paksaan, beberapa saat setelah minum susu (Depkes 2007). Gumoh bukan muntah yang diawali dengan rasa mual dan penuh di perut. Gumoh biasanya terjadi pada bayi secara spontan, saat asam lambung naik membawa isi lambung kembali ke kerongkongan. Gumoh berkelanjutan juga bisa naik dan masuk ke saluran pernapasan hingga ke paru-paru, hal ini bisa menyebabkan asma, pneumonia, atau radang paru, bahkan sindrom kematian bayi mendadak. Gumoh yang berlebihan dapat menyebabkan berbagai komplikasi yang akan mengganggu pertumbuhan bayi. Gumoh pada bayi bisa dianggap normal selama tidak mengganggu pertumbuhan.(http//: Kuliah Bidan.Wordpress.com, 2008).

Catatan Depkes 2010 Sekitar 70 persen bayi berumur di bawah 4 bulan mengalami gumoh minimal 1 kali setiap harinya, dan kejadian tersebut menurun sesuai dengan bertambahnya usia hingga 8-10 persen pada umur 9-12 bulan dan 5 persen pada umur 18 bulan.

Gumoh dapat terjadi karena klep penutup lambung belum berfungsi sempurna. Dari mulut, susu akan masuk ke saluran pencernaan atas, baru kemudian ke lambung. Di antara kedua organ tersebut terdapat klep penutup lambung. Pada bayi, klep ini biasanya belum berfungsi sempurna. Akibatnya, kalau bayi dalam posisi yang salah susu akan keluar dari mulut. Ibu sering menyusui sambil tiduran dengan posisi miring sementarara bayi tidur telentang. Akibatnya, cairan tersebut tidak masuk ke saluran pencernaan tetapi ke saluran pernafasan yang menyebabkan bayi gumoh. (Suparyanto, 2007).

Rumusan masalah dalam peneltian ini adalah adakah hubungan antara pengetahuan ibu tentang cara menyendawakan bayi sesudah menyusui dengan kejadian Gumoh pada Bayi Usia 0-6 
bulan? Tujuan umum penelitian ini adalah mengetahui hubungan antara pengetahuan ibu tentang cara menyendawakan bayi sesudah menyusui dengan kejadian gumoh pada bayi usia 0-6 bulan. Sedangkan tujuan khususnya adalah: 1. Mengidentifikasi Pengetahuan ibu tentang Cara menyendawakan bayi usia 0-6 bulan; 2 . Mengidentifikasi Kejadian Gumoh pada bayi usia 0-6 bulan di Kelurahan Lontar Surabaya.

\section{BAHAN DAN METODE}

Desain penelitian yang digunakan yaitu deskriptif dengan studi korelasi. Studi korelasi sendiri merupakan studi yang bertujuan untuk menemukan ada tidaknya hubungan (Arikunto,2006: 270). Populasi dalam penelitian ini adalah semua Ibu yang memiliki bayi usia 0-6 bulan dengan kejadian gumoh di Wilayah kerja Puskesmas Lontar Surabaya. Sampelnya yaitu seluruh jumlah populasi yang diambil dalam wilayah kerja Puskesmas Lontar Surabaya pada bulan Oktober sampai November 2011. Berdasarkan data yang diperoleh dari posyandu di wilayah kerja Puskesmas Lontar surabaya tahun 2011 total populasi bayi sebanyak 30 , maka sampel yang diambil sebanyak 30 responden.

Pada penelitian ini variabel independennya adalah pengetahuan $\mathrm{lbu}$ dengan indikator variabel meliputi cara pencegahan gumoh dan teknik menyendawakan. Pada penelitian ini variabel dependennya adalah kejadian gumoh dengan indikator variabel frekuensi Gumoh yaitu tidak pernah, jarang, sering.

Data yang akan digali dalam penelitian ini adalah data primer,data yang diperoleh dari sumber asli, meliputi beberapa pertanyaan yang ditujukan pada ibu mengenai Gumoh yang dikumpulkan dengan kuesioner dan ceklist. Teknik analisis data yang digunakan dalam penelitian ini adalah Teknik Spearman Rank Order Corelation. Yaitu korelasi yang digunakan untuk mencari hubungan antara variabel dengan skala ordinal dan skala ordinal (Jonathan, 2006).

\section{HASIL DAN PEMBAHASAN}

\section{Karakteristik lbu dari Bayi yang Pernah Mengalami Kejadian Gumoh}

1. Usia: sebagian besar ibu berusia antara 21-30 tahun sebanyak $20 \quad(66,7 \%)$ orang, yang berusia 31- 40 tahun sebanyak $7(23,3 \%)$ dan sebagian kecil ibu berusia $<20$ tahun sebanyak 3 $(10 \%)$.

2. sebagian besar ibu dengan latar belakang pendidikan terakhir SMP/SMA sebanyak $25(83,33 \%)$ orang dan sebagian kecil ibu dengan latar belakang pendidikan terakhir SD sebanyak $5(16,67 \%)$.

3. sebagian besar pekerjannya sebagai ibu rumah tangga sebanyak 25 $(83,33 \%)$ orang dan sebagian kecil pekerjaannya sebagai karyawan swasta sebanyak $5(16,67 \%)$.

\section{Distribusi Frekwensi Berdasarkan Pengetahuan Ibu Tentang Cara Menyendawakan}

Tabel 1 menunjukkan bahwa dari 30 responden sebagian besar ibu yang mempunyai pengetahuan cukup sebanyak $21(70 \%)$ orang, yang mempunyai pengetahuan kurang sebanyak $6(20 \%)$ dan sebagian kecil ibu yang mempunyai pengetahuan baik sebanyak $3(10 \%)$.

Tabel 1. Distribusi frekwensi berdasarkan pengetahuan ibu tentang cara menyendawakan di Wilayah kerja Puskesmas Lontar Surabaya 2011.

\begin{tabular}{|c|c|c|}
\hline Pengetahuan Ibu & $f$ & $\%$ \\
\hline Baik & 3 & 10 \\
\hline Cukup & 21 & 70 \\
\hline Kurang & 6 & 20 \\
\hline Jumlah & 30 & 100 \\
\hline
\end{tabular}

Sumber : data primer 2011

Sebagian ibu sebanyak 20\% masih kurang mengetahui tentang cara menyendawakan bayi. Kurangnya informasi 
atau pengetahuan tentang cara menyendawakan bayi setelah menyusui dapat mengakibatkan kematian bila terjadi gumoh. Adanya pengetahuan yang cukup dalam menyendawakan bayi maka akan dapat mengurangi tigkat kejadian gumoh.

\section{Frekwensi kejadian gumoh pada bayi usia 0 - 6 bulan}

Tabel 2 menunjukkan bahwa dari 30 responden sebagian besar bayi yang jarang terjadi gumoh sebanyak 26 (86,7\%) bayi, yang sering terjadi gumoh sebanyak 3 $(10 \%)$ dan sebagian kecil bayi yang tidak pernah terjadi gumoh sebanyak 1 ( $3,3 \%)$ bayi.

Tabel 2. Distribusi frekwensi berdasarkan kejadian gumoh pada bayi usia $0-6$ bulan di Wilayah Puskesmas Lontar Surabaya 2011.

\begin{tabular}{|c|c|c|}
\hline Kejadian Gumoh & $f$ & $\%$ \\
\hline Sering & 3 & 10 \\
\hline Jarang & 26 & 86,7 \\
\hline Tidak Pernah & 1 & 3,3 \\
\hline Jumlah & 30 & 100 \\
\hline
\end{tabular}

Sumber : data primer 2011

Berdasarkan tabel 2, kejadian gumoh dapat saja terjadi pada bayi usia 0 6 bulan. Meskipun dari data terlihat bahwa kejadian gumoh ini kemungkinan kecil terjadi namun para ibu perlu untuk memiliki pengetahuan dalam mengatasinya.

\section{Pengetahuan lbu Tentang Cara Menyendawakan Berdasarkan Umur}

Dari tabel 3 menunjukkan bahwa ibu yang mempunyai pengetahuan baik yaitu pada umur $21-30$ sebanyak $3(10 \%)$ responden. Yang mempunyai pengetahuan cukup yaitu sebagian besar pada umur 2130 tahun sebanyak $15(50 \%)$ responden, pada umur $<20$ tahun dan umur 31-40 tahun masing- masing sebanyak 2(6,67\%). Yang mempunyai pengetahuan kurang yaitu pada umur 21-30 tahun sebanyak $4(13,3)$ responden, pada umur $<20$ tahun dan 31-40 tahun masing- masing sebanyak $1(3,33 \%)$ responden31 - 40 tahun sebanyak 3 (10\%) responden.
Tabel 3. Distribusi frekwensi pengetahuan ibu tentang cara menyendawakan berdasarkan Umur.

\begin{tabular}{|c|c|c|c|c|c|c|c|c|}
\hline \multirow[t]{3}{*}{ Umur } & \multicolumn{6}{|c|}{$\begin{array}{c}\text { Pengetahuan Ibu tentang cara } \\
\text { menyendawakan }\end{array}$} & \multirow{2}{*}{\multicolumn{2}{|c|}{$\Sigma$}} \\
\hline & \multicolumn{2}{|c|}{ Baik } & \multicolumn{2}{|c|}{ Cukup } & \multicolumn{2}{|c|}{ Kurang } & & \\
\hline & $f$ & $\%$ & $f$ & $\%$ & $f$ & $\%$ & $f$ & $\%$ \\
\hline$<20$ tahun & - & - & 2 & 6,67 & 1 & 3,33 & 3 & 10 \\
\hline $\begin{array}{l}21-30 \\
\text { tahun }\end{array}$ & 3 & 10 & 15 & 50 & 4 & 13,3 & 22 & 73,3 \\
\hline $\begin{array}{l}31-40 \\
\text { tahun }\end{array}$ & - & - & 2 & 6,67 & 1 & 3,33 & 5 & 16,67 \\
\hline Jumlah & 3 & 10 & 21 & 70 & 6 & 20 & 30 & 100 \\
\hline
\end{tabular}

Sumber : data primer 2011

\section{Pengetahuan Ibu Tentang Cara Menyendawakan Berdasarkan Pendidikan.}

Dari tabel 4 menunjukkan bahwa ibu yang mempunyai pengetahuan baik sebanyak $3(10 \%)$ responden berpendidikan SMP/SMA. Sebagian besar yang mempunyai pengetahuan cukup sebanyak $21 \quad(70 \%)$ responden berpendidikan SMP/SMA . Yang mempunyai pengetahuan kurang sebanyak 6 (20\%) responden berpendidikan SD dan SMP/SMA.

Tabel 4. Distribusi frekwensi pengetahuan ibu tentang cara menyendawakan berdasarkan Pendidikan.

\begin{tabular}{|c|c|c|c|c|c|c|c|c|}
\hline \multirow[t]{3}{*}{ Pendidikan } & \multicolumn{6}{|c|}{$\begin{array}{c}\text { Pengetahuan Ibu tentang } \\
\text { cara menyendawakan }\end{array}$} & \multirow{2}{*}{\multicolumn{2}{|c|}{$\Sigma$}} \\
\hline & \multicolumn{2}{|c|}{ Baik } & \multicolumn{2}{|c|}{ Cukup } & \multicolumn{2}{|c|}{ Kurang } & & \\
\hline & $f$ & $\%$ & $f$ & $\%$ & $f$ & $\%$ & $f$ & $\%$ \\
\hline SD & - & - & - & - & 5 & 16,7 & 5 & 16,7 \\
\hline SMP/SMA & 3 & 10 & 21 & 70 & 1 & 3,33 & 25 & 83,3 \\
\hline AK/PT & - & - & - & - & - & - & - & - \\
\hline Jumlah & 3 & 10 & 21 & 70 & 6 & 20 & 30 & 100 \\
\hline
\end{tabular}

Sumber : data primer 2011

\section{Pengetahuan Ibu Tentang Cara Menyendawakan Berdasarkan Pekerjaan}

Dari tabel 5 menunjukkan bahwa ibu yang mempunyai pengetahuan baik sebanyak $3 \quad(6,7 \%)$ responden yang pekerjaannya IRT. Yang mempunyai pengetahuan cukup Sebagian besar sebanyak $21 \quad(70 \%)$ responden yang pekerjaanya IRT dan Swasta. Dan yang Mempunyai pengetahuan kurang sebanyak $6(20 \%)$ responden yang pekerjaanya IRT dan Swasta. 
Tabel 5.Distribusi Frekwensi Pengetahuan Ibu tentang cara menyendawakan Berdasarkan Pekerjaan.

\begin{tabular}{|c|c|c|c|c|c|c|c|c|}
\hline \multirow{3}{*}{ Pekerjaan } & \multicolumn{6}{|c|}{$\begin{array}{c}\text { Pengetahuan Ibu tentang cara } \\
\text { menyendawakan }\end{array}$} & \multicolumn{3}{|c|}{$\Sigma$} \\
\cline { 2 - 8 } & \multicolumn{3}{|c|}{ Baik } & Cukup & \multicolumn{2}{|c|}{ Kurang } & \multicolumn{2}{|c}{$\Sigma$} \\
\cline { 2 - 8 } & f & $\%$ & f & $\%$ & f & $\%$ & f & $\%$ \\
\hline IRT & 3 & 10 & 18 & 60 & 4 & 13,3 & 25 & 83,3 \\
\hline Swasta & - & - & 3 & 10 & 2 & 6,67 & 5 & 16,7 \\
\hline PNS & - & - & - & - & - & - & - & - \\
\hline Jumlah & 3 & 10 & 21 & 70 & 6 & 20 & 30 & 100 \\
\hline
\end{tabular}

Sumber : data primer 2011

\section{Hubungan Pengetahuan lbu tentang cara menyendawakan dengan kejadian gumoh pada \\ bayi $0-6$ bulan di Wilayah kerja Puskesmas Lontar Surabaya.}

Dari tabel 5.9 menunjukkan bahwa sebagian kecil $3(10 \%)$ responden yang mempunyai pengetahuan baik dengan kejadian gumoh jarang dan tidak pernah. Sebagian besar $21 \quad(70 \%)$ responden mempunyai pengetahuan yang cukup dengan kejadian gumoh jarang dan $6(20 \%)$ responden mempunyai pengetahuan kurang dengan kejadian gumoh sering dan jarang.

Tabel 6. Hubungan Pengetahuan Ibu Tentang Cara Menyendawakan dengan Kejadian Gumoh pada Bayi 0 - 6 Bulan di Wilayah Kerja Puskesmas Lontar Surabaya.

\begin{tabular}{|c|c|c|c|c|c|c|c|c|}
\hline \multirow{3}{*}{$\begin{array}{c}\text { Kejadian } \\
\text { Gumoh }\end{array}$} & \multicolumn{6}{|c|}{$\begin{array}{c}\text { Pengetahuan Ibu tentang cara } \\
\text { menyendawakan }\end{array}$} & \multirow{2}{*}{\multicolumn{2}{|c|}{$\Sigma$}} \\
\hline & \multicolumn{2}{|c|}{ Baik } & \multicolumn{2}{|c|}{ Cukup } & \multicolumn{2}{|c|}{ Kurang } & & \\
\hline & $f$ & $\%$ & $f$ & $\%$ & $f$ & $\%$ & $f$ & $\%$ \\
\hline Sering & - & - & - & - & 3 & 10 & 3 & 10 \\
\hline Jarang & 2 & 6,67 & 21 & 70 & 3 & 10 & 26 & 86,67 \\
\hline Tdk pernah & 1 & 3,33 & - & - & - & - & 1 & 3,33 \\
\hline Jumlah & 3 & 10 & 21 & 70 & 6 & 20 & 30 & 100 \\
\hline$\alpha=0,05$ & & rho ta & $=0$ & & & $a b$ & $g=$ & \\
\hline
\end{tabular}

Sumber : data primer 2011

Dari hasil uji statistik dengan menggunakan rumus spearman Rank Order Correlation diketemukan rho hitung $=0,94>$ rho tabel $=0,364$ dengan tingkat kemaknaan $\alpha=0,05$ yang mempunyai arti bahwa hubungan antara pengetahuan ibu tentang cara menyendawakan bayi sesudah menyusu dengan kejadian gumoh pada bayi usia $0-6$ bulan di Wilayah kerja Puskesmas Lontar Surabaya sangat tinggi. Korelasi positif mempunyai arti hubungan bersifat searah. Searah disini maksudnya , semakin tinggi pengetahuan ibu tentang cara menyendawakan bayi , maka semakin tinggi pula jumlah bayi yang tidak mengalami gumoh.

\section{SIMPULAN DAN SARAN}

Berdasarkan hasil penelitian maka dapat disimpulkan sebagai berikut: 1) Dari 30 responden sebagian besar ibu yang mempunyai pengetahuan cukup sebanyak $21(70 \%)$ orang, yang mempunyai pengetahuan kurang sebanyak $6(20 \%)$ dan sebagian kecil ibu yang mempunyai pengetahuan baik sebanyak $3(10 \%) ; 2$ ) Dari 30 responden di wilayah kerja Puskesmas Lontar Surabaya sebagian besar angka kejadian gumoh pada bayi sebanyak $21(70 \%)$ orang tergolong jarang ; 3) Terdapat hubungan antara pengetahuan ibu tentang cara menyendawakan bayi sesudah menyusu dengan kejadian gumoh pada bayi usia 0- 6 bulan di kelurahan lontar.

Saran yang dapat disampaikan dari hasil peneltitian ini yaitu: 1) Bagi ibu-ibu sangatlah penting mencari berbagai pengetahuan tentang gumoh dan cara penanggulangannya; 2) Bagi Pihak Layanan Kesehatan (Puskesmas atau Lembaga yang terkait) harus selalu memberikan dan meningkatkan layanan penyuluhan kepada masyarakat.

\section{DAFTAR ACUAN}

Arifin, Zaenal.2010. Metodologi penelitian Pendidikan Filosofit, Teori, dan Aplikasinya Edisi Keempat. Lentera Cendekia: Surabaya.

\section{Depkes.2007. Kejadian Gumoh}

Handajani, Dewi, dkk. Panduan Lengkap untuk Ibu merawat Bayi Usia 0-6 bulan.PT Aspira Pemuda: Jakarta.

Kelly, Paula. 2010. Buku Saku Asuhan Neonatus dan Bayi. EGC:Jakarta.Kompas.2009. 
Manuaba.1998. Ilmu Kebidanan dan

Kandungan.EGC: Jakarta.

Notoadmojo, Soekidjo. 2003. Metode Penelitian Kesehatan. Rineka cipta : Jakarta.

Notoadmojo, Soekidjo. 2005. Metode Penelitian Kesehatan. Rineka cipta : Jakarta.

Nursalam. 2005. Konsep dan penerangan Metode penelitian IImu Keperawatan.Salemba : Jakarta.

Supartini, Sumiati, Subandowo.2009. Buku Panduan Penyusunan Usulan penelitian Proposal dan Karya Tulis IImiah (KTI). Unipa : Surabaya.

Vivian. 2010. Asuhan Neonatus dan Anak.

Salemba : Jakarta.

www. Depkes.co.id. diakses tanggal 10 maret 2010. 